\title{
PERSEPSI MASYARAKAT TENTANG OBAT PATEN DI APOTEK PERDOS FARMA KOTA MAKASSAR
}

\author{
Ayu Wijaya \\ STIKES Amanah Makassar \\ email : ayuwijayadam@gmail.com
}

\begin{abstract}
ABSTRAK
Obat merupakan salah satu komponen yang tidak tergantikan dalam pelayanan kesehatan. Akses terhadap obat terutama obat esensial merupkan kewajiban bagi pemerintah dan institusi pelayanan kesehatan baik publik maupun swasta.Adapun tujuan penelitian ini adalah telah diketahui persepsi masyarakat tentang obat di Apotek Perdos Farma Kota Makassar. Jenis penelitian yang digunakan dalam penelitian ini adalah jenis deskriptif kualitatif dengan metode kuisioner pada responden terpilih yang memenuhi kriteria inklusi di Apotek Perdos Farma Kota Makassar 2021. Populasi dalam penelitian ini adalah semua masyarakat yang datang berkunjung ke Apotek Perdos Farma Kota Makassar. Sampel dalam penelitian ini adalah sebagaian masyarakat yang membeli obat paten di Apotek Perdos Farma Kota Makassar yang memenuhui kriteria inklusi sebanyak 36 Orang.Walaupun berbeda harga itu tidak menjadikan mutu obat paten lebih bagus dibanding obat generik. Obat paten dan obat generik sama saja, karena tetap menggunakan zat berkhasiat yang sama serta telah lulus dalam CPOB. Jadi apapun jenisnya konsumen tidak perlu mengkhawatirkan dari segi mutu kerena obat paten dan obat generik sama saja, sehingga masyarakat golongan ekonomi menengah kebawah tidak harus mengkonsumsi obat paten.
\end{abstract}

Kata Kunci : Apotek, Masyarakat, Obat Paten

\section{PENDAHULUAN}

Pembangunan pelayanan kesehatan bertujuan meningkatkan kesadaran, kemauan, dan kemampuan hidup sehat dan memiliki akses terhadap pelayanan kesehatan yang bermutu secara adil dan merata. Obat merupakan salah satu komponen yang tidak tergantikan dalam pelayanan kesehatan. Akses terhadap obat terutama obat esensial merupkan kewajiban bagi pemerintah dan institusi pelayanan kesehatan baik publik maupun swasta (Munadhir, 2012).

Pelayanan kefarmasian merupakan kegiatan yang bertujuan untuk mengidentifikasi, mencegah, dan menyelesaikan masalah terkait obat. Tuntutan pasien dan masyarakat akan peningkatan mutu pelayan kefarmasian ,mengharuskan adanya perluasa dari paradigma lama yang berorientasi kepada produk (Drug Oriented) menjadi paradigma baru yang berorientasi pada pasien (Patien Oriented) dengan filosofi pelayanan kefarmasian/Phamaceutical Care (Menkes RI, 2014).

Di tengah begitu maraknya jenis dan jumlah obat yang beredar di pasaran,informasi terkait obat yang berisi elemen-elemen asuhan kefarmasian menjadi amat penting untuk tercapainya pengobatan yang efektif. Mahalnya biaya pengobatan bersumber obat terjadi karena kurangnya informasi, sehingga obat digunakan secara tidak rasional dan bertanggung jawab (ISO, 2014).
Di satu sisi melalui Peraturan Kementrian Kesehatan No. HK. 02. 02/ MENKES /068/1/2010 tentang kewajiban menggunakan obat generik di fasilitas pelayanan kesehatan pemerintah di mana dokter di puskesmas dan di rumah sakit pemerintah belum berjalan secara optimal. Apoteker juga di beri kewenangan untuk mengganti obat merek dagang/obat paten dengan obat generik yang sama komponen aktifnya, dengan persetujuan dokter atau pasien (Permenkes, 2010).

Hasil penelitian sebelumnya menyimpulkan bahwa, penggunaan obat paten di Apotek RSUD Lakipada tergolong masih rendah $(30,66 \%)$ bila di bandingkan dengan obat generik $(68,82 \%)$. Adapun fenomena yang terlihat di Apotek Perdos Farma penggunaan obat paten lebih diminati di banding obat generik dan masih banyak pasien yang datang membeli obat dengan membawa kemasan obat paten (Kristira, 2011).

\section{METODE}

Lokasi, Populasi dan sampel Penelitian

Jenis penelitian yang digunakan dalam penelitian ini adalah jenis deskriptif kualitatif dengan metode kuisioner pada responden terpilih yang memenuhi kriteria inklusi di Apotek Perdos Farma Kota Makassar 2021. Penelitian ini dilaksanakan di Apotik Perdos Farma Kota Makassar pada tanggal Mei-Juni 2021.opulasi dalam penelitian ini adalah semua masyarakat yang datang berkunjung ke Apotek Perdos Farma Kota Makassar. Sampel dalam penelitian ini adalah 
sebagaian masyarakat yang membeli obat paten di Apotek Perdos Farma Kota Makassar yang memenuhui kriteria inklusi sebanyak 36 Orang. Pengambilan sampel dengan menggunakan metode accidental sampling yaitu pengambilan sampel dilakukan saat penelitian berlangsung sehingga sampel yang diperoleh adalah sampel yang ada tersedia pada waktu itu (Suyanto, 2011).

Pengambilan sampel ditentukan dengan berdasarkan kriteria inklusi sebagai berikut :

a. Masyarakat yang datang berkunjung dan membeli obat paten di Apotek Perdos Farma

b. Usia minimal $\geq 22$ tahun

c. Bisa membaca dan menulis

\section{HASIL PENELITIAN}

Tabel 1 Distribusi Frekuensi Persepsi Masyarakat Tentang Pengetahuan Obat Paten di Apotek Perdos Farma Kota Makassar

\begin{tabular}{|c|c|c|}
\hline Pengetahuan & n & \% \\
\hline Tahu & 23 & 63,9 \\
\hline TidakTahu & 13 & 36,1 \\
\hline Total & 36 & 100.0 \\
\hline
\end{tabular}

Dari tabel 1 dapat dilihat bahwa persepsi masyarakat tentang obat paten di Apotek Perdos Farma Kota Makassar, dengan persepsi tahu tentang obat paten sebanyak 23 orang dan yang tidakmengetahuisebanyak 13 orang. Dari total respondensebanyak 36 orang.

Tabel 2 Distribusi Frekuensi Persepsi Masyarakat Tentang Harga Obat Paten di Apotek Perdos Farma Kota Makassar

\begin{tabular}{|c|c|c|}
\hline Harga & $\mathbf{n}$ & $\mathbf{\%}$ \\
\hline Mahal & 26 & 72,2 \\
\hline \hline Total & 36 & 100.0 \\
\hline
\end{tabular}

Dari tabel 2 dapatdilihatbahwapersepsimasyarakattentanghargaobat paten di ApotekPerdosFarma Kota Makassar, denganpersepsitentanghargaobat paten yang mengatakanmahalsebanyak 26 orang dan yang mempunyaipersepsihargaobat paten murahsebanyak 10 orang. Dari total respondensebanyak 36 orang.

Tabel 3 Distribusi Frekuensi Persepsi Masyarakat Tentang Kemasan dan Logo Obat Paten di Apotek Perdos Farma Kota Makassar

\begin{tabular}{|c|c|c|}
\hline Kemasandan logo & n & \% \\
\hline Tahu & 19 & 52,8 \\
\hline TidakTahu & 17 & 47,2 \\
\hline Total & 36 & 100.0 \\
\hline
\end{tabular}

Dari tabel 3 dapat dilihat bahwa perseps imasyarakat tentang Kemasan dan logo obat paten di Apotek Perdos Farma Kota Makassar, yang mengetahui tentang kemasandan logo obat paten sebanyak 19 orang dan yang tidak mengetahui sebanyak 17 orang. Dari total respondensebanyak 36 orang.

Tabel 4 Distribusi Frekuensi Persepsi Masyarakat Tentang Jenis Obat Paten di Apotek Perdos Farma Kota Makassar

\begin{tabular}{|c|c|c|}
\hline Jenis & n & \% \\
\hline Tahu & 22 & 61,1 \\
\hline TidakTahu & 14 & 38,9 \\
\hline Total & 36 & 100.0 \\
\hline
\end{tabular}


Dari tabel 4 dapat dilihat bahwa persepsi masyarakat tentang Jenisobat paten di Apotek Perdos Farma Kota Makassar, dengan persepsi tentang jenisobat paten yang mengetahuisebanyak 22 orang dan yang tidak mengetahui sebanyak 14 orang. Dari total responden sebanyak 36 orang.

Tabel 5 Distribusi Frekuensi Persepsi Masyarakat Tentang Sumber Informasi Obat Paten di Apotek Perdos Farma Kota Makassar

\begin{tabular}{|c|c|c|}
\hline Sumber informasi & n & \% \\
\hline Tahu & 26 & 72.2 \\
\hline TidakTahu & 10 & 27.8 \\
\hline Total & 36 & 100.0 \\
\hline
\end{tabular}

Dari tabel 5 dapat dilihat bahwa persepsi masyarakat tentang sumber informasobat paten di Apotek PerdosFarma Kota Makassar, dengan persepsi tentang sumber informas iobat paten yang mengetahui sebanyak 26 orang dan yang tidak mengtahui sebanyak 10 orang. Dari total responden sebanyak 36 orang.

Tabel 6 Distribusi Frekuensi Persepsi Masyarakat Tentang pelayanan Obat Paten di Apotek Perdos Farma Kota Makassar

\begin{tabular}{|c|c|c|}
\hline Pelayanan & n & \% \\
\hline Tahu & 25 & 69,4 \\
\hline TidakTahu & 11 & 30,6 \\
\hline Total & 36 & 100.0 \\
\hline
\end{tabular}

Dari tabel 6 dapat dilihat bahwa persepsi masyarakat tentang pelayanan obat paten di Apotek Perdos Farmakota Makassar, dengan persepsi baik tentang pelayanan obat paten yang mengetahui sebanyak 25 orang dan yang tidak mengetahui sebanyak 11 orang. Dari total responden sebanyak 36 orang.

Tabel 7 Rekapitulasi Persepsi Masyarakat Tentang Obat Paten di Apotek Perdos Farma Kota Makassar

\begin{tabular}{|c|c|c|c|c|}
\hline \multirow{2}{*}{ Persepsi } & \multicolumn{3}{|c|}{ Jumlah } & \multicolumn{2}{c|}{ Persentase(\%) } \\
\cline { 2 - 5 } & Baik & Kurang & Baik & Kurang \\
\hline Pengetahuan & 23 & 13 & 63,9 & 36,1 \\
\hline Harga & 26 & 10 & 72,2 & 27,8 \\
\hline Kemasandan logo & 19 & 17 & 52,8 & 47,2 \\
\hline JenisObat Paten & 22 & 14 & 61,1 & 38,9 \\
\hline SumberInformasi & 26 & 10 & 72,2 & 27,8 \\
\hline Pelayanan & 25 & 11 & 69,4 & 30,6 \\
\hline Jumlah & \multicolumn{3}{|c|}{141} & \multicolumn{2}{c|}{30} \\
\hline Rata ${ }^{2}$ Responden & \multicolumn{3}{|c|}{63,3} \\
\hline Persentase(\%)
\end{tabular}

\section{PEMBAHASAN}

Pengetahuan tentang obat yang benar tentunya bisa dikatakan merupakan sesuatu hal yang penting. Hal tersebut karena obat merupakan komponen penting dalam pelayanan kesehatan karena intervensi obat diperlukanan dalam sebagian besar upaya kesehatan, baik upaya preventif, promotif, kuratif dan rehabilitasi.

Salah satu yang mempengaruhi persepsi masyarakat adalah mengenai pengetahuan dari obat paten itu sendiri di mana masyarakat mengetahui tentang obat paten yaitu pada saat mereka berobat ke Rumah sakit dan Apotek. Dari 36 responden terdapat 23 orang $(63,9 \%)$ yang mengetahui tentang obat paten, dan 13 orang $(36,1 \%)$ yang tidak mengetahui tentang obat paten. Jawaban ini menunjukan bahwa mayoritas responden mengetahui betul tentang obat paten tersebut.
Dari segi persepsi masyarakat tentang harga obat paten memang lebih mahal karena disubsidi atau diatur oleh perusahan swasta berdasarkan harga eceran tertinggi,dan Masyarakat mengetahui tentang harga obat paten pada saat mereka membeli obat paten di Apotek. Dari 36 responden terdapat 26 orang $(72,2 \%)$ yang mempunyai persepsi bahwa harga obat paten lebih mahal, dan 10 orang $(27,8 \%)$ yang mempunyai persepsi bahwa harga obat paten tidak terlalu mahal.

Dari segi persepsi masyarakat tentang kemasan obat paten, tentu lebih bagus dan menarik,masyarakat mengetahui tengtang kemasan dan logo obat paten dari dokter,Apoteker dan sosial media. Dari 36 responden terdapat 19 orang $(52,8 \%)$ yang mengetahui kemasan dan obat paten dan $17(47,2 \%)$ yang tidak mengetahui tentang kemasan obat paten. Dengan mengetahui kemasan 
obat paten, akan membuat masyarakat tidak bingung dalam memilih obat.

Dari segi persepsi masyarakat tentang jenis obat paten yang dikonsumsi tentu perlu kita ketahui obat apa yang akan kita konsumsi, jangan sampai mengkonsumsi obat tapi tidak tahu apa fungsi dari obat tersebut, Masyarakat mengetahui jenis obat paten pada saat mereka membeli obat di Apotek. Dari 35 responden terdapat 22 orang $(61,1 \%)$ yang mengetahui jenis obat paten yang pernah dikonsumsi dan 14 orang $(38,9 \%)$ yang tidak mengetahuinya.

Sumber informasi memang penting bagi masyarakat dalam memilih obat. Kebanyakan persepsi masyarakat tentang informasi obat paten didapatkan dari dokter, apoteker, perawat, bidan, dan media sosial. Dari 36 responden sebanyak 26 orang $(72,2 \%)$ yang mendapatkan informasi tentang obat paten dan terdapat 10 orang $(27,8 \%)$ yang tidak mendapatkan informasi. Disini dapat dilihat bahwa informasi sangat dibutuhkan oleh masyarakat dalam memilih obat paten yang akan dipilih.

Dari segi persepsi masyarakat terhadap pelayanan di apotek dalam memilih obat paten sangat di butuhkan penjelasan dari apoteker atau asisten apoteker tentang penggunaan obat paten. Dari 36 responden terdapat 25 orang $(69,4 \%)$ yang mengerti tentang penggunaan obat paten, dan terdapat 11 orang $(30,7 \%)$ yang tidak mengerti penjelasan dari apoteker atau asisten apoteker.

Pada dasarnya obat paten memeng lebih mahal dibandingkan dengan obat generik, ini disebabkan salah satunya karena obat paten memerlukan biaya yang besar untuk riset penemuan, memerlukan biaya untuk iklan dan promosi.

Kesadaran masyarakat akan konsumsi obat paten masih tinggi. Hal ini disebabkan masih adanya anggapan bahwa obat paten yang harganya mahal mempunyai kualitas dan mutu yang baik di banding obat generik.

Walaupun berbeda harga itu tidak menjadikan mutu obat paten lebih bagus dibanding obat generik. Obat paten dan obat generik sama saja, karena tetap menggunakan zat berkhasiat yang sama serta telah lulus dalam CPOB. Jadi apapun jenisnya konsumen tidak perlu mengkhawatirkan dari segi mutu kerena obat paten dan obat generik sama saja, sehingga masyarakat golongan ekonomi menengah kebawah tidak harus mengkonsumsi obat paten.

\section{KESIMPULAN}

Berdasarkan hasil pembahasan terhadap studi persepsi masyarakat tentang obat paten di Apotek Perdos Farma Kota Makassar 2021 maka dapat di simpulkan bahwa dari 36 responden terdapat 24 orang $(66.7 \%)$ yang mempunyai persepsi tau terhadap obat paten dan sebanyak 12 orang $(33,3 \%)$ yang mempunyai persepsi tidak tau terhadap obat paten.

\section{SARAN}

Adapun saran dari penulis yaitu : Diharapkan agar masyarakat tidak hanya memilih obat dari segi harga karena harga tidak menjamin kuaalitas dan mutu obat Diharapkan agar lebih meningkatkan pelayanan dalam memberikan informasi tentang obat baik itu obat paten maupun obat generik Diharapkan kepada peneliti selanjutnya untuk melakukan penelitian tehadap persepsi masyarakat tentang obat paten mengenai penggunaannya.

\section{DAFTAR PUSTAKA}

Aryo Bogadenta, 2013, Manajemen Pengelolaan Apotek, D-Medika, Jogjakarta.

Bimo Walgito, 2011, Teori-teori Psikologi Sosial, Andi Offest, Jogjakarta

Herri Zan Pieter, dkk, 2012, Pengantar Psikologi dalam Keperwatan, Kencana Prenada Media Grup, Jakarta

IAI, 2014, ISO Indonesia Volume 48, Jakarta

Moh, Anief, 2014, Manajemen Farmasi, Gadjah Mada University Press, Jogjakarta

Permenkes RI Nomor HK.02.02/MENKES/068/I/2010, Kewajiban Menggunakan Obat Generik di Fasilitas Pelayanan Kesehatan Pemerintah, Depkes

Rantetasak Kristira,2011, Studi Penggunaan Obat Generik dan Obat Paten di RSUD Lakipadada Kabupaten Tanah Toraja, KTI Stikes Nani Hasanuddin Makassar

Rosleny Marliany, 2014, Psikologi Umum, CV Pustaka Setia, Bandung 
Suyanto,2011, Metodologi dan Aplikasi Penelitian Keperawatan, Nuha Medica, Jogjakarta Syamsuni,2012, Ilmu Resep, Kedokteran EGC, Jakarta

Tan Hoan Tjay, dkk, 2010, Obat-obat Penting, PT Elex Media Komputindo, Jakarta 